\title{
Flow cytometry as a tool to assess the effects of gamma radiation on the viability, growth and metabolic activity of fungal spores
}

\author{
N. Mesquita a, ${ }^{a}$, A. Portugal ${ }^{a}$, G. Piñar ${ }^{b}$, J. Loureiro $^{a}$, A.P. Coutinho ${ }^{a}$, J. Trovão ${ }^{a}$, \\ I. Nunes ${ }^{\mathrm{c}}$, M.L. Botelho ${ }^{\mathrm{c}}$, H. Freitas ${ }^{\mathrm{a}}$ \\ ${ }^{a}$ Centre for Functional Ecology, Department of Life Sciences, University of Coimbra, PO Box 3046, 3001-401 Coimbra, Portugal \\ ${ }^{\mathrm{b}}$ Institute of Applied Microbiology, Department of Biotechnology, Vienna Institute of Bio Technology (VIBT), University of Natural Resources and \\ Life Sciences, Muthgasse 11, A-1190 Vienna, Austria \\ ${ }^{c}$ Unit of Physics and Accelerators, Nuclear and Technological Institute, Estrada Nacional 10, 2686-953 Sacavém, Portugal
}

\section{A R T I C L E I N F O}

\section{Article history:}

Received 31 January 2012

Received in revised form

8 May 2012

Accepted 10 May 2012

Available online 9 June 2012

\section{Keywords:}

Flow cytometry

Spore viability

Fungal viability

Metabolic activity

Spore growth

Filamentous fungi

Gamma radiation

Dihydroethidium

Reactive oxygen species

ROS

\begin{abstract}
A B S T R A C T
Flow cytometry is often used for viability and vitality assessment in bacteria and yeasts. However, its application to the study of fungal spore development is uncommon, probably due to the difficulties in successfully staining these cells.

In the current study, we used flow cytometry for the first time to assess the effects of a disinfection treatment on the survival, growth and metabolic activity of fungal spores (Penicillium chrysogenum, Aspergillus nidulans and Aspergillus niger) submitted to gamma radiation $(0-15 \mathrm{kGy})$. The Forward and Side-Scatter parameters of the cytometer were used to assess the differences in size and complexity of particles. Furthermore, two fluorescent dyes were used: Propidium Iodide to assess the membrane integrity and spore viability, in a culture-independent procedure; and Dihydroethidium to measure the changes in metabolic activity of irradiated spores in their first $10 \mathrm{~h}$ of growth in a liquid culture medium.

Our results support that flow cytometry is a valuable tool in assessing different biological parameters and biocide effects, as it allowed accurate determination of the viability, growth and metabolic activity of gamma-irradiated spores. The fluorescence of Propidium Iodide was $5-7 \times$ more intense in unviable spores. The Dihydroethidium fluorescence increase was associated with faster growth. Control and low radiation doses allowed the germination and growth of spores, while higher doses led to growth inhibition and lower fluorescence.
\end{abstract}

(c) 2012 Elsevier Ltd. All rights reserved.

\section{Introduction}

Flow cytometry (FCM) allows the simultaneous analysis of several characteristics of particles from a heterogeneous population (size, complexity, fluorescence). The light scattered by each particle is filtered, and routed to appropriate detectors that measure the magnitude of pulses, which represent the amount of scattered light. Flow cytometry has many different applications in several fields of research: blood cell counts, viability and vitality of both bacteria and yeasts and microbial discrimination (Davey and Kell, 1996; Veal et al., 2000; Davey, 2002). Each particle is analysed individually, and several hundred can be analysed each second, providing information on single particle properties instead of population averages. It is therefore a powerful analysis tool for qualitative and quantitative purposes.

\footnotetext{
* Corresponding author. Tel.: +351 239855210; fax: +351 239855211.

E-mail address: nuno@plasticsounds.com (N. Mesquita).
}

The size and complexity of particles is assessed using lightscattering measurements; forward-scattered light (FSC) provides information on the particle size, whereas side-scattered light (SSC) is associated with particle complexity. However, using fluorescent stains and probes, many other cell properties, and cell contents can be analysed. According to the flow cytometer settings and stain specifications, various fluorochromes can be used simultaneously to assess different particle parameters (Shapiro, 2003). The use of multiple parameters to detect and select different particles is one of the technical advantages of flow cytometry, as one can differentiate fungal propagules from biotic debris as well as other cells (Prigione et al., 2004). These analyses can be performed right after a given treatment is applied, without the need to re-inoculate, incubate and perform colony counts, in a process that would usually require several days.

Propidium Iodide is a fluorescent dye that binds to DNA, and is generally unable to penetrate the membrane of live cells, however it stains dead cells, working as a dye-exclusion viability probe 
(Williams et al., 1998; Steinkamp et al., 1999) and it is suitable for the study of fungal conidia (Brul et al., 1997). When excited by a $488-523 \mathrm{~nm}$ laser, it fluoresces orange-red, and can be detected using a $562-588 \mathrm{~nm}$ band pass filter. It is commonly used in the evaluation of cell viability or to assess DNA content in cell cycle analysis by flow cytometry. Experiments with bacterial cells show that PI staining is usually independent of cell growth phase, and that cells can be stored in glycerol for long periods while retaining the stain (Williams et al., 1998).

Dihydroethidium is a chemically reduced ethidium derivative that has no positive charge. When chemically reduced, this dye exhibits blue fluorescence within the cytoplasm. In viable cells, it can be oxidized to ethidium by reactive oxygen species (ROS), which intercalates with DNA, fluorescing red (Breeuwer and Abee, 2000). In general, spores and conidia have thick and resistant cell walls to protect protoplasts from physical, chemical, and biological damage, but sometimes this inhibits effective staining (Prigione et al., 2004). In this study, controls were made using an epifluorescence microscope (Nikon Optiphot) to confirm that the fluorochromes were actually entering the cells when expected.

Gamma rays are electromagnetic waves with high penetrating power that are able to pass through materials without leaving any harmful residue, which is a big advantage when compared with other disinfection treatments (Adamo et al., 1998, 2001; Da Silva et al., 2006). This sterilization treatment directly damages cell DNA through ionization, induces mutations, and ultimately kills the cell. Through the radiolysis of cellular water, it also promotes the formation of reactive oxygen species (ROS), free radicals and peroxides that cause single and double strand DNA breakages (McNamara et al., 2003). Fungi have successfully been inactivated from different materials, such as paper, wood and soil, using radiation doses ranging from 6 to $15 \mathrm{kGy}$ (Hanus, 1985; Pointing et al., 1998; McNamara et al., 2003; Da Silva et al., 2006).

Reactive oxygen species are also formed in the course of metabolic activity, and can therefore be used as metabolic indicators, since aerobic energy transduction depends on a complex electron transport chain and a proton pumping system in the mitochondrial membrane, which is susceptible to electron leakage (Bradner and Nevalainen, 2003). This leads to the formation of the superoxide anion, which is a ROS that can promote the formation of other ROS molecules, and at higher concentrations, they can damage cellular components and lead to cellular dysfunctions (Osiewacz, 2002). They may serve as regulators of fungal population development, for example, by inhibiting growth in excessively dense spore suspensions. In fact, self-suppression of germination in dense spore suspensions can be explained by the deficiency of vital resources, and self-intoxication with vital activity products: germinating spores produce ROS, which can suppress spore development.

Some fungi cope with increasing ROS concentrations using different strategies: by decreasing the surface area; by developing other mechanisms to limit the penetration of external substances. Melanin and other anti-oxidants, eventually help to balance the formation of ROS inside the cell. Reactive oxygen species regulate the most vitally important processes in fungi: phase development change, intercellular communications, and protection from interspecies competition (Gessler et al., 2007).

The aims of this work were to analyse the viability of irradiated fungal spores with flow cytometry without the need to culture them; and, coincidently, to assess the metabolic activity and growth of fungal spores in their first $10 \mathrm{~h}$ of growth in a liquid culture medium. Different doses of gamma radiation (0-15 kGy) were applied to fungal spores of three different species - Penicillium chrysogenum, Aspergillus niger and Aspergillus nidulans - whose strains were isolated from library documents in a previous work (Mesquita et al., 2009). They are common contaminant fungi of documents, and have been reported in different substrates: paper, parchment, leather, textiles and film (Zyska, 1997; Sterflinger, 2010; Sterflinger and Pinzari, 2011). All three species are potentially harmful to humans (Bennett and Kilch, 2003; Samson et al., 2010).

Most microorganisms living in, or on, objects of art usually depend on special nutrients, so only a minority of species can be cultivated under laboratory conditions (Scharbereiter-Gurtner et al., 2001). Cultivation-independent methods enable the assessment of slower growing or even non culturable microorganisms and, in some cases, render the analysis faster and less expensive.

\section{Materials and methods}

\subsection{Tested fungal species}

Three fungal species were selected for this study $-P$. chrysogenum, A. niger and A. nidulans. They were isolated previously by Mesquita et al. (2009). P. chrysogenum is a ubiquitous cellulolytic fungus that is a halotolerant, mesophile and psychrotolerant species. Both $A$. niger and $A$. nidulans are cosmopolitan cellulolytic species that are also xerophilic and mesophilic, although they are able to grow at warm temperatures.

\subsection{Spore suspensions}

The three isolates were re-cultured in PDA medium plates, and incubated at $28{ }^{\circ} \mathrm{C}$ until sporulating cultures were obtained (6-8 days). Fresh conidia were harvested by washing with a sterile saline solution $(0.9 \% \mathrm{w} / \mathrm{v})$ containing Silwet L-77 surfactant $(0.01 \%$ $\mathrm{v} / \mathrm{v}$ ) (GE Silicones, USA), and this fluid was filtered using $10 \mu \mathrm{m}$ Partec CellTrics filters (Partec, Germany) to remove the residual mycelia. To avoid the presence of particles which were smaller in size, washing of the fungal plates was performed gently to exclude as much debris as possible from the spore suspensions.

The presence of spores was confirmed using an optical microscope. The original concentration of the spore suspensions was estimated using the Neubauer chamber method, and adjusted to $10^{7}$ spores $/ \mathrm{ml}$. Samples were stored in the cold $\left(4^{\circ} \mathrm{C}\right)$ and without light until the irradiation procedure.

\subsection{Irradiation procedure}

Spore suspensions were prepared in triplicate for each species tested, using $2 \mathrm{ml}$ micro tubes, and these were irradiated in a Cobalt 60 experimental source (Precisa 22) located at the Nuclear and Technological Institute campus (Sacavém, Portugal). Five gamma radiation doses were applied: 3, 6, 9, 12 and $15 \mathrm{kGy}$, using a dose rate ranging between $2.45 \mathrm{kGy} / \mathrm{h}$ and $2.87 \mathrm{kGy} / \mathrm{h}$. Absorbed doses were monitored using calibrated routine dosimeters (maximum variation range of $\pm 2.5 \%$; Perspex, Harwell). After the irradiation procedure, the tubes containing the irradiated spore suspensions were stored in the cold $\left(4^{\circ} \mathrm{C}\right)$ and without light until the flowcytometry analyses.

\subsection{Flow cytometric analysis}

Growth, viability and metabolic activity of fungal spores were assessed in a Partec CyFlow Space (Partec, Germany) flow cytometer, equipped with a green solid-state laser (532 nm/30 mW). The flow rate was adjusted to approximately 300 particles $\mathrm{s}^{-1}$. To remove any particles smaller than spores from the analysis, the discriminator was defined for the particle size (FSC) just under the lowest spore signals. The obtained cytograms were analysed using FlowJo 8 software suite (www.flowjo.com), in particular, debris and cell fragments were removed by gating. 


\subsubsection{Growth assessment}

Samples were prepared using cytometer tubes $(3.5 \mathrm{ml}$, $55 \times 12 \mathrm{~mm}$; Sarstedt, Nümbrecht, Germany), with $1 \mathrm{ml}$ of Potato Dextrose Broth (PDB; Difco Laboratories, Sparks, MD, USA) liquid culture medium, and $1 \mathrm{ml}$ of the corresponding spore suspension, for final concentration of $5 \times 10^{6}$ spores $/ \mathrm{ml}$. Samples were incubated at $28{ }^{\circ} \mathrm{C}$, for the duration of this experiment $(10 \mathrm{~h})$. At four different time points $-0,4,7$ and $10 \mathrm{~h}$ of incubation $-100 \mu \mathrm{l}$ of sample were added to a flow cytometry tube with $1.9 \mathrm{ml}$ of distilled water for a final spore concentration of $2.5 \times 10^{5}$ spores/ $\mathrm{ml}$. These were mixed by inversion and then analysed in the flow cytometer.

To assess the effects of different gamma radiation doses on the growth of the fungal spores, this experiment was replicated for each species using the sets of irradiated doses $(0,3,6,9$ and $12 \mathrm{kGy}$ ). The $15 \mathrm{kGy}$ dose results are not displayed in this analysis, since growth was completely inhibited.

\subsubsection{Spore viability: propidium iodide staining}

To assess spore viability without the use of culture media, filtered sterile water was used instead.

Cytometer tubes $(3.5 \mathrm{ml})$ were prepared for each species and irradiation dose, with $1 \mathrm{ml}$ of sterilized water, and $1 \mathrm{ml}$ of the corresponding irradiated spore suspension for a final concentration of $5 \times 10^{6}$ spores/ml. From this suspension, $100 \mu$ l were added to a flow cytometry tube with $50 \mu$ l of Propidium Iodide stock solution ( $1 \mathrm{mg} / \mathrm{ml}$; Sigma, St Louis, USA) and $1.85 \mathrm{ml}$ of distilled water (final concentration of $2.5 \times 10^{5}$ spores/ml and $25 \mu \mathrm{g} / \mathrm{ml}$ of PI). Tubes were mixed by inversion and analysed in the cytometer after 10 min of staining.

\subsubsection{Metabolic activity: dihydroethidium staining}

For each isolate, cytometer tubes $(3.5 \mathrm{ml})$ were prepared with $1 \mathrm{ml}$ of Potato Dextrose Broth (PDB; DIFCO, USA) liquid culture medium, and $1 \mathrm{ml}$ of the corresponding spore suspension (final concentration of $5 \times 10^{6}$ spores $\left./ \mathrm{ml}\right)$. Samples were incubated at $28{ }^{\circ} \mathrm{C}$, for the duration of this experiment $(10 \mathrm{~h})$.

At four different time points $-0,4,7$ and $10 \mathrm{~h}$ of incubation $100 \mu$ l were added to $1.85 \mathrm{ml}$ of distilled water in a flow cytometry tube, for a final spore concentration of $2.5 \times 10^{5}$ spores $/ \mathrm{ml}$, and stained with $50 \mu \mathrm{l}$ of the DHE stock solution $(1 \mathrm{mg} / \mathrm{ml}$, prepared in dimethylsulfoxide; Sigma, USA). Tubes were mixed by inversion and analysed in the flow cytometer after $10 \mathrm{~min}$ of staining time. As DHE fluoresces bright red $(605 \mathrm{~nm})$ when oxidized by ROS, so it was detected in the red channel of the flow cytometer.

To assess the effects of different gamma radiation doses on the metabolic activity of the fungal spores, this experiment was replicated for each species using the sets of irradiated doses $(0,3,6$, 9, $12 \mathrm{kGy}$ ). The $15 \mathrm{kGy}$ dose was not used in this analysis, since growth was completely inhibited.

\section{Results and discussion}

In this study, forward (FSC) and side (SSC) scatter were used as growth indicators in the early stages of development of three different species of filamentous fungi in PDB culture medium. Also, using two fluorescent stains, other physiological aspects were analysed: propidium iodide was employed to assess the membrane integrity and spore viability (without using culture media) while dihydroethidium was used to measure the changes in the metabolic activity of irradiated spores, during their first $10 \mathrm{~h}$ of growth in PDB liquid culture medium. The values for all flow cytometer readings are presented in arbitrary units (A.U.).

Most of the signals from contaminant debris in spore suspensions were excluded during data analysis with the use of gates and regions. In this work, these gates were set to include all particles that were at least as big (FSC) and as complex (SSC) as the smaller spores of the population, thus removing from analysis much of the smaller debris. However, particles with size similar to the spore population could not be filtered using this strategy, which could produce false positives/negatives during analysis. Collected data were methodically gated to remove smaller debris from analysis, therefore the effects caused by the presence of such particles in the obtained results were negligible.

\subsection{Growth assessment in non-irradiated spores}

Throughout the duration of the assay, there was an increase in size and in complexity of spores, as revealed by the geometric mean (GM) values of the FSC and SSC (Table 1, see $0 \mathrm{kGy}$; Fig. 1). After the first $4 \mathrm{~h}$ of incubation, a clear increase in spore size (FSC) was observed, generally with smaller changes in complexity (SSC). This is probably due to spore swelling, which happens before effective germination. This phenomenon was confirmed by observations of the spores under the microscope.

After $10 \mathrm{~h}$ of incubation, average FSC values nearly doubled for $A$. niger and $A$. nidulans, and increased by approximately $20 \%$ for $P$. chrysogenum. Side scatter values increased in a more pronounced manner after $4 \mathrm{~h}$ of incubation, for $A$. niger and $P$. chrysogenum, and after $7 \mathrm{~h}$ for $A$. nidulans, as a consequence of the initial hyphae development (also confirmed by microscope observation), meaning that this method can also be used as an indicator for that stage of development. After $10 \mathrm{~h}$, SSC had increased $36.5 \%$ for P. chrysogenum, 37\% for A. niger and 75\% for A. nidulans (Table 1).

Table 1

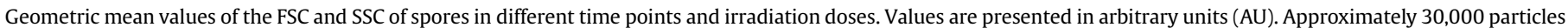
were analysed in each run.

\begin{tabular}{|c|c|c|c|c|c|c|c|c|c|}
\hline \multirow[t]{2}{*}{ Species } & \multirow[t]{2}{*}{ Dose } & \multicolumn{4}{|l|}{ FSC } & \multicolumn{4}{|l|}{ SSC } \\
\hline & & $00 \mathrm{~h}$ & $04 \mathrm{~h}$ & $07 \mathrm{~h}$ & $10 \mathrm{~h}$ & $00 \mathrm{~h}$ & $04 \mathrm{~h}$ & $07 \mathrm{~h}$ & $10 \mathrm{~h}$ \\
\hline \multirow[t]{4}{*}{ P. chrysogenum } & 00 kGy & 6.26 & 6.58 & 7.16 & 7.52 & 10.40 & 12.40 & 14.00 & 14.20 \\
\hline & 03 kGy & 5.52 & 6.21 & 6.48 & 6.66 & 11.00 & 12.50 & 13.90 & 14.00 \\
\hline & 06 kGy & 5.06 & 5.39 & 5.39 & 5.43 & 10.70 & 10.90 & 11.40 & 11.20 \\
\hline & 12 kGy & 4.89 & 4.78 & 4.87 & 4.46 & 10.50 & 9.65 & 10.70 & 8.13 \\
\hline \multirow[t]{4}{*}{ A. niger } & 00 kGy & 7.65 & 11.70 & 12.50 & 14.50 & 44.40 & 46.90 & 58.40 & 60.80 \\
\hline & 03 kGy & 7.79 & 9.69 & 11.20 & 12.20 & 37.40 & 39.50 & 48.80 & 57.30 \\
\hline & 06 kGy & 7.70 & 7.77 & 8.99 & 9.05 & 49.60 & 43.60 & 56.70 & 53.30 \\
\hline & $12 \mathrm{kGy}$ & 8.11 & 7.91 & 8.12 & 8.32 & 47.50 & 43.20 & 48.00 & 47.30 \\
\hline \multirow[t]{4}{*}{ A. nidulans } & 00 kGy & 16.30 & 19.50 & 22.40 & 29.70 & 60.80 & 63.20 & 71.00 & 106.00 \\
\hline & 03 kGy & 15.50 & 17.20 & 17.30 & 17.60 & 51.50 & 51.50 & 53.50 & 58.40 \\
\hline & 06 kGy & 7.98 & 7.98 & 8.01 & 7.41 & 42.90 & 45.30 & 43.60 & 39.80 \\
\hline & $12 \mathrm{kGy}$ & 6.82 & 6.51 & 6.75 & 6.64 & 37.40 & 34.70 & 35.90 & 34.90 \\
\hline
\end{tabular}



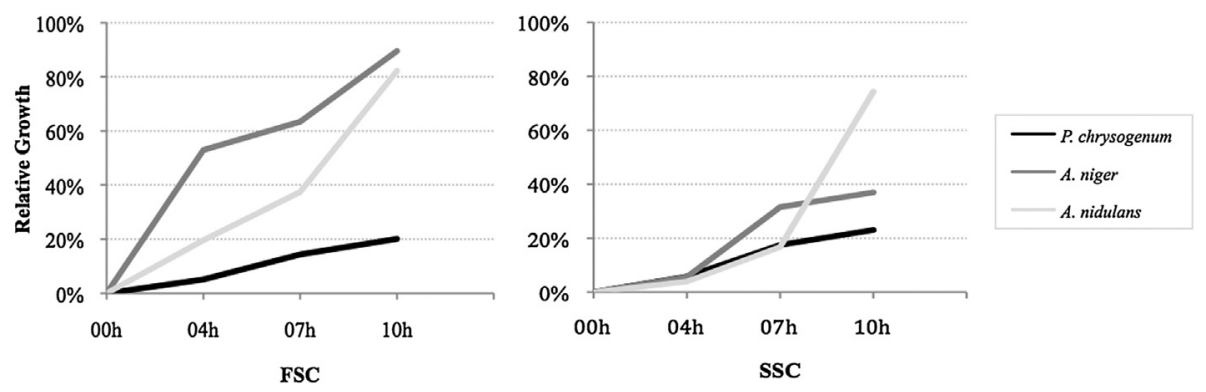

Fig. 1. Relative growth in size (FSC) and complexity (SSC) in the first $10 \mathrm{~h}$ of growth (when compared to initial spore size).

\subsection{Effects of gamma irradiation on spore growth}

When spores were subjected to gamma irradiation, FSC and SSC values were affected in a dose dependant manner (Table 1). The $9 \mathrm{kGy}$ dose results are not displayed in Table 1 or Fig. 2, since they were very similar to the $12 \mathrm{kGy}$ results.

The initial spore size after irradiation differed considerably among each species: whereas for $A$. niger, radiation doses up to $12 \mathrm{kGy}$ had little effects on the FSC or SSC values (in fact, the size of irradiated spores was actually larger at the end of the experiment than in the control). For P. chrysogenum and A. nidulans, a negative correlation between FSC values and gamma irradiation doses was found (Table 1). In P. chrysogenum, 3, 6 and $12 \mathrm{kGy}$ doses reduced the average size of spores in 10, 20 and $22 \%$ respectively; comparatively, smaller changes were found in the SSC values. In A. nidulans, irradiation with $3 \mathrm{kGy}$ decreased spore size by $5 \%$; in contrast, doses of 6 and $12 \mathrm{kGy}$ caused a decrease of 50\% and 58\% respectively. These data strongly suggest that most spores were severely harmed with these radiation doses, and it is possible that the cell wall structure was compromised; nevertheless such a big decrease in size was unexpected.

In lower irradiation doses ( $3 \mathrm{kGy}$ ), irrespective of the species, some spores kept growing, although at slower rates than in the control. Indeed, at almost every time point, FSC and SSC values of irradiated spores (all species) were lower than in the control. After $10 \mathrm{~h}$, FSC values were $12 \%$ lower than the control for P. chrysogenum, $16 \%$ for A. niger, and $40 \%$ for $A$. nidulans. With exception, of A. nidulans, where a significant decrease was observed after $10 \mathrm{~h}$, for the other species, SSC values were similar to those of the control (Table 1).

When $6 \mathrm{kGy}$ were applied, only some of the P. chrysogenum and A. niger spores grew, causing a slight increase in FSC values in the first 4-7 h. And if A. niger was able to continue growing, $P$. chrysogenum was not, suggesting that even initially viable spores can be rendered unviable after a few hours (Table 1).

A dose of $12 \mathrm{kGy}$ inhibited fungal growth completely in all species, as revealed by the FSC values, which generally decreased over time. At this high dose, SSC was also affected in all species, especially after $10 \mathrm{~h}$. Some spores that might have resisted this dose were certainly detrimentally affected by gamma radiation, and were unlikely to survive or to develop normally (Table 1 ). This is supported by the data provided in Fig. 2, which displays the FSC values of irradiated spores from all species, after 0 and $10 \mathrm{~h}$ of incubation in PDB. The effects on growth were generally proportional to the applied radiation dose, with higher doses causing slower growth. In untreated spores, the maximum FSC values
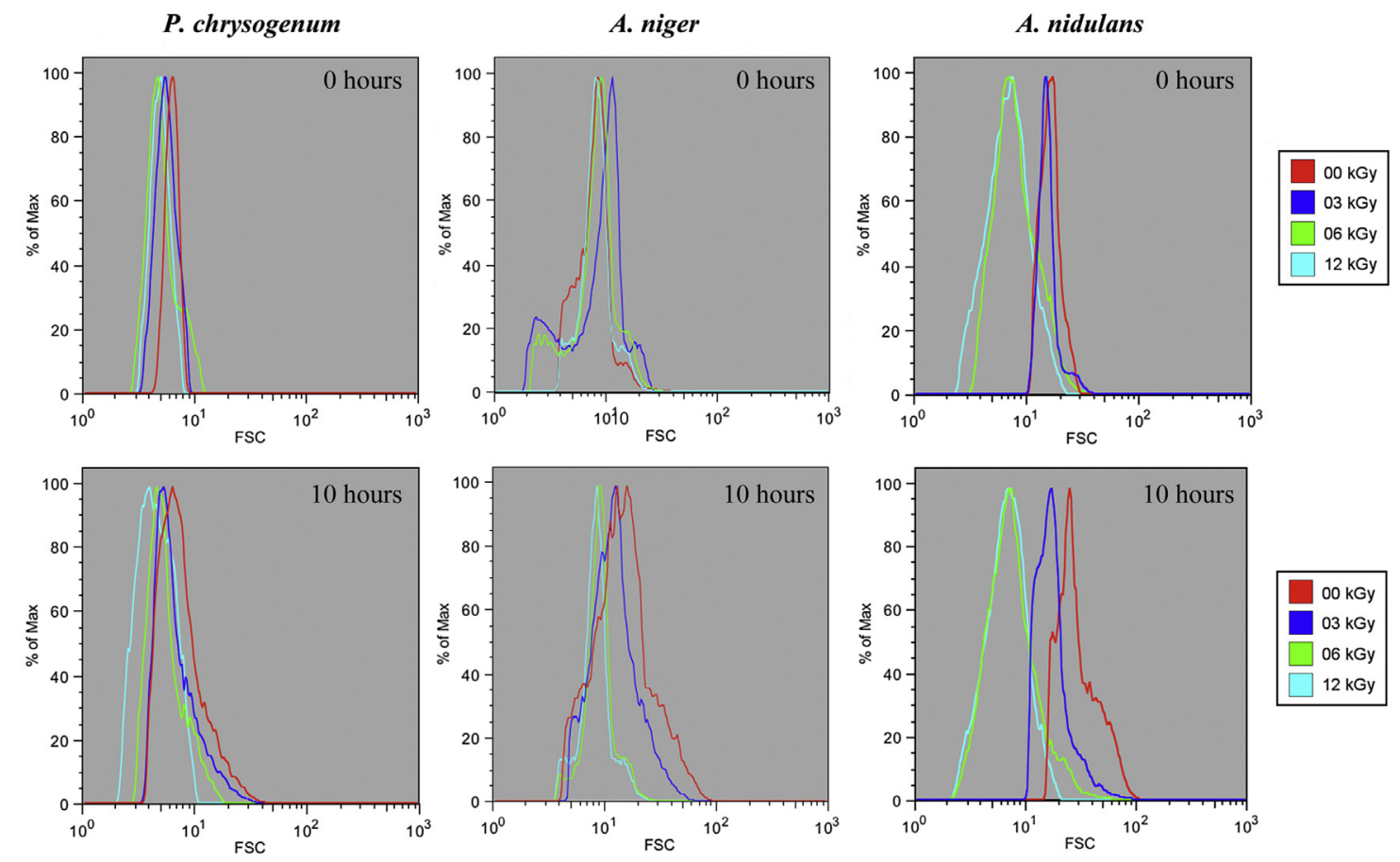

Fig. 2. FSC of irradiated spores after 0 and $10 \mathrm{~h}$ of incubation in PDB. Approximately 30,000 particles were analysed in each run. 
Table 2

Percentage of unviable spores after irradiation with different doses, according to the PI fluorescence intensity (uncultured spores). Approximately 30,000 particles were analysed in each run.

\begin{tabular}{lccllll}
\hline \multicolumn{7}{c}{ Radiation dose } \\
\cline { 2 - 7 } & $0 \mathrm{kGy}$ & $3 \mathrm{kGy}$ & $6 \mathrm{kGy}$ & $9 \mathrm{kGy}$ & $12 \mathrm{kGy}$ & $15 \mathrm{kGy}$ \\
\hline P. chrysogenum & 3.93 & 70.2 & 82.3 & 95.6 & 96.9 & 98.5 \\
A. niger & 0.83 & 6.54 & 89.3 & 90.6 & 90.1 & 91.2 \\
A. nidulans & 12.5 & 42.8 & 83.3 & 89.2 & 89.4 & 95.1 \\
\hline
\end{tabular}

(size of bigger spores present in the sample), showed an increase of 3-fold for A. nidulans, and 4-fold for P. chrysogenum and A. niger (Fig. 2). Information gathered from other incubation periods and radiation doses support that some of the irradiated spores that started to grow, had a development arrest after a few hours (data not shown).

We successfully monitored the size and complexity of spores during the first hours of germination, and assessed the radiation effects in these parameters, indicating that this method can provide interesting results on fungal spore growth in liquid culture medium, and that this is in agreement with previous research (e.g. Bradner and Nevalainen, 2003).

\subsection{Spore viability assessment}

In this assay our aim was to test a medium-independent analysis of the viability of fungal spores after gamma irradiation treatments; thus water was used instead of culture medium. Propidium Iodide has already been used in flow cytometry to assess the viability of yeasts and bacteria (Green et al., 1994; Xiao et al., 2010), but in fungal spores it is not a common procedure. Our analyses revealed that in all tested species, independently of the irradiation dose, PI fluorescence intensity was 5-7 times higher in irradiated than in non-irradiated spores (Table 2; Fig. 3). Similar differences in fluorescence intensity have been described for yeasts and bacteria (Green et al., 1994; Xiao et al., 2010).

As expected, in general, there was a positive correlation between irradiation doses and the percentage of unviable cells (Table 2 ). The $3 \mathrm{kGy}$ irradiation dose had a more relevant effect in $P$. chrysogenum (70.2\% of unviable spores), than in A. nidulans (42.8\%) and A. niger (6.54\%). This higher resistance of $A$. niger to $3 \mathrm{kGy}$ dose may be probably a consequence of its high melanin content, being capable to absorb electromagnetic radiation (Dadachova and Casadevall, 2008). However, this was not as effective in protecting the interior of the cell when higher doses were used. Nearly 1-log reduction (90\%) of viable counts was obtained after exposure to $6 \mathrm{kGy}$. $P$. chrysogenum was the most sensitive species in this test, with
Table 3

Geometric mean values of the DHE fluorescence of spores in different time points. Values are presented in arbitrary units (AU). Approximately 30,000 particles were analysed in each run.

\begin{tabular}{llcccc}
\hline \multirow{2}{*}{ Dose } & \multicolumn{2}{c}{ DHE fluorescence } & & \\
\cline { 3 - 6 } & & $00 \mathrm{~h}$ & $04 \mathrm{~h}$ & $07 \mathrm{~h}$ & $10 \mathrm{~h}$ \\
\hline P. chrysogenum & $\mathbf{0 0} \mathbf{~ k G y}$ & $\mathbf{5 . 7 5}$ & $\mathbf{7 1 . 5}$ & $\mathbf{1 1 9}$ & $\mathbf{1 6 0}$ \\
& $03 \mathrm{kGy}$ & 39.3 & 53.1 & 55 & 72.8 \\
& $06 \mathrm{kGy}$ & 35.8 & 32.9 & 24.9 & 23.6 \\
& $09 \mathrm{kGy}$ & 37 & 26.8 & 26.5 & 22.4 \\
& $12 \mathrm{kGy}$ & 39.2 & 30.9 & 30.5 & 27.9 \\
A. niger & $\mathbf{0 0} \mathbf{~ k G y}$ & $\mathbf{8 . 2 1}$ & $\mathbf{7 0 . 3}$ & $\mathbf{7 7 . 5}$ & $\mathbf{8 9 . 8}$ \\
& $03 \mathrm{kGy}$ & 22.9 & 67.9 & 74.8 & 73.3 \\
& $06 \mathrm{kGy}$ & 33.3 & 35.5 & 34.6 & 34.9 \\
& $09 \mathrm{kGy}$ & 22.2 & 21.9 & 24.3 & 18.1 \\
A. nidulans & $12 \mathrm{kGy}$ & 54.7 & 49.7 & 61 & 50.4 \\
& $\mathbf{0 0} \mathbf{~ k G y}$ & $\mathbf{1 3 . 2}$ & $\mathbf{3 0 . 4}$ & $\mathbf{9 4}$ & $\mathbf{1 5 9}$ \\
& $03 \mathrm{kGy}$ & 28.8 & 23.7 & 33 & 24.2 \\
& $06 \mathrm{kGy}$ & 9.97 & 9.47 & 9.98 & 11.6 \\
& $09 \mathrm{kGy}$ & 11.1 & 10.2 & 9.18 & 9.55 \\
& $12 \mathrm{kGy}$ & 9.43 & 9.54 & 8.99 & 9.97 \\
\hline
\end{tabular}

a higher percentage of unviable spores in almost all irradiation doses (98.5\% at $15 \mathrm{kGy}$, almost 2-log).

In general, the $D_{10}$ dose (that corresponds to $90 \%$ of inactivation) fell between 6 and $9 \mathrm{kGy}$ for all three species. In spore survival analysis, direct comparison of $D_{10}$ values between different published works is somewhat difficult because of different testing conditions: the inoculum strain, concentration, irradiation support (water, culture media or others) or even dose/rate values (Saleh et al., 1988; Blank and Corrigan, 1995).

\subsection{Metabolic activity of non-irradiated spores}

Non-irradiated spores of all species presented a very low DHE fluorescence at $0 \mathrm{~h}$, an indicator of very little or even nonexistent metabolic activity. This was expected since spores need some time to initiate germination after incubation. Thus, no significant amount of ROS were produced in spores at the beginning of the test, and the detected DHE fluorescence signal was consequently very low (Table 3; Fig. 4).

After $4 \mathrm{~h}$, there was an obvious increase in fluorescence, with a 10-fold increase for $P$. chrysogenum and A. niger (Table 3, 0 kGy). In comparison, $A$. nidulans started to grow more slowly, as shown in Table 1 , so instead, nearly $10 \mathrm{~h}$ were required for this species to display a similar increase.

It was interesting to see that fluorescence consistently increased before actual cell growth occurred. As displayed in Table 1, the growth of most $P$. chrysogenum increased only after 7;
P. chrysogenum

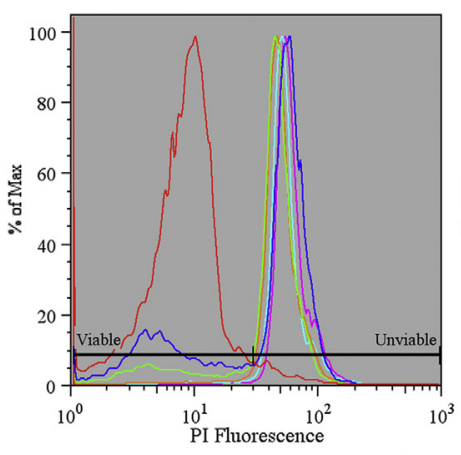

A. niger

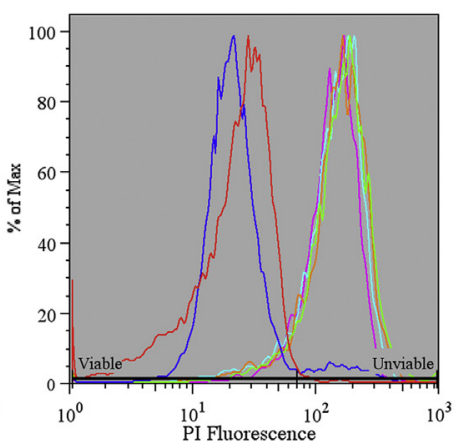

A. nidulans

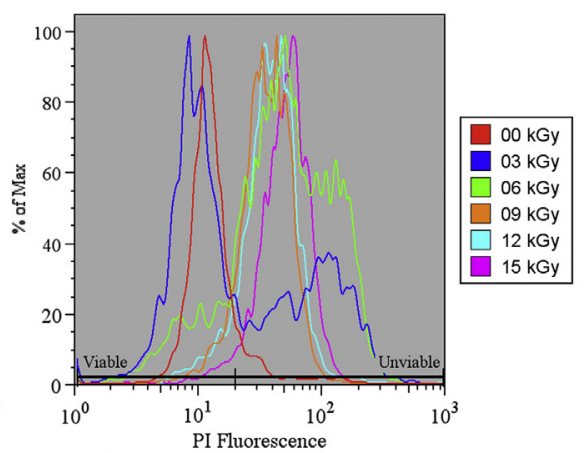

Fig. 3. PI Fluorescence in gamma irradiated spores after irradiation with different doses (at $0 \mathrm{~h}$ ). Approximately 30,000 particles were analysed in each run. 

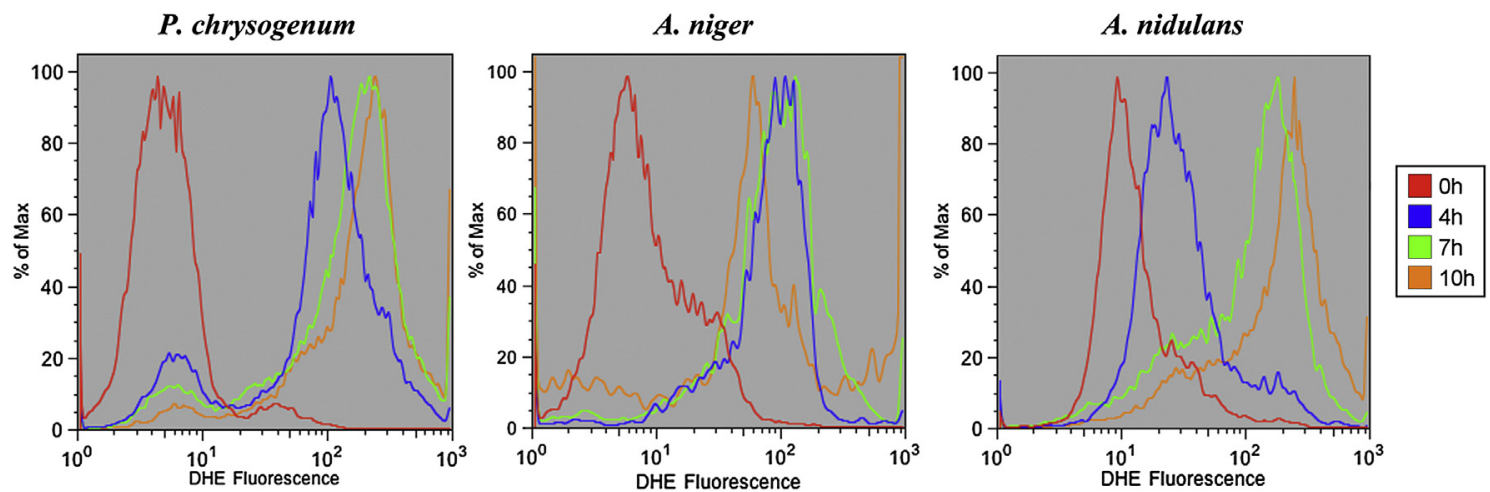

Fig. 4. DHE Fluorescence of non-irradiated spores after 0 and $10 \mathrm{~h}$. Approximately 30,000 particles were analysed in each run.
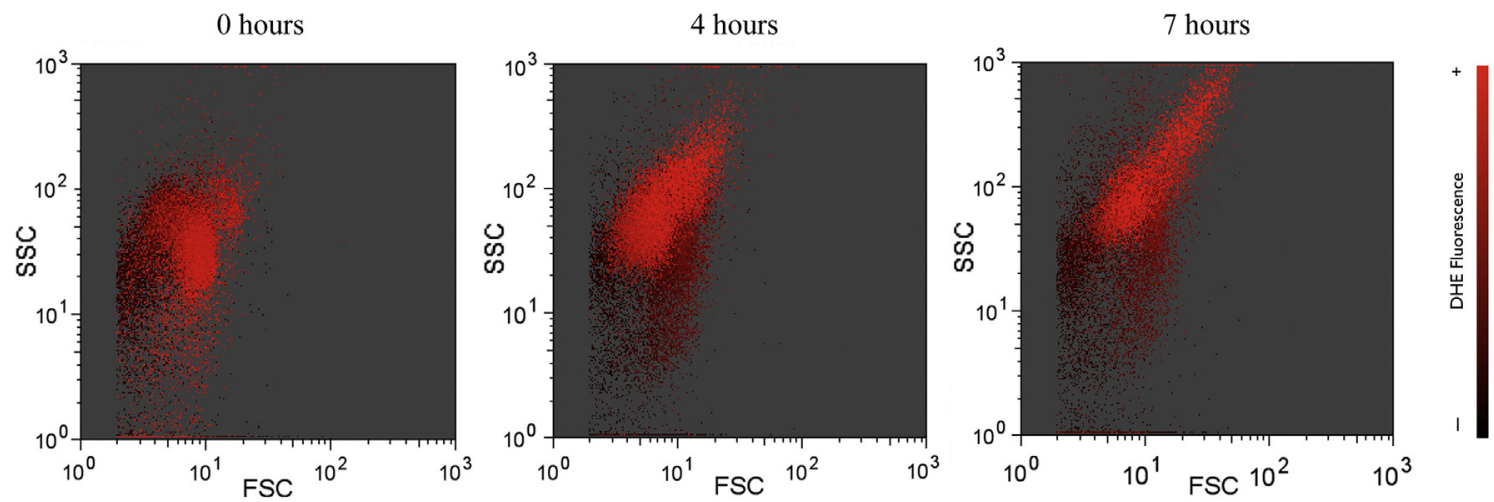

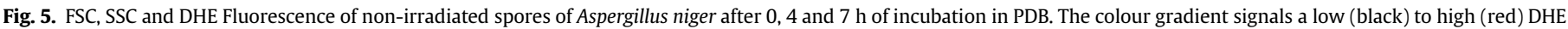

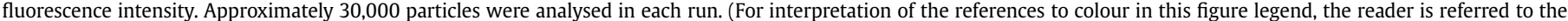
web version of this article.)

still, an increase in DHE fluorescence was already clear after $4 \mathrm{~h}$ (almost a 12-fold increase), and continued until the end of the experiment. It is likely that an increase in metabolic activity happens prior to spore germination, while the biological functions of the dormant spores are re-initiating. Accordingly, A. niger spores were actively growing after $4 \mathrm{~h}$ (50\% increase in FSC; Fig. 1), and thus were already very active at that stage, as confirmed by the DHE fluorescence that had already increased 9-fold (Table 3, $0 \mathrm{kGy}$ ). In the subsequent hours, fluorescence continued to increase, but at lower rates, suggesting that $A$. niger spore activity was already optimized after a $4-7 \mathrm{~h}$ incubation period. Fig. 5 shows that after 0,4 and $7 \mathrm{~h}$, spores that were bigger presented a higher DHE fluorescence, meaning that they were metabolically more active.

During the first $4 \mathrm{~h}, A$. nidulans, the increase in DHE fluorescence was not as significant as in the other species, but after $7 \mathrm{~h}$ and $10 \mathrm{~h}$ the values were already comparable (Table 3). Furthermore, A. nidulans spores presented the highest complexity values, which had almost doubled after $10 \mathrm{~h}$ (Table 1). Even though it started to grow slower, $A$. nidulans presented a big increase in FSC and SSC values after $10 \mathrm{~h}$ (Table $1,0 \mathrm{kGy}$ ), which is also supported by the DHE fluorescence results (Table 3, 0 kGy).
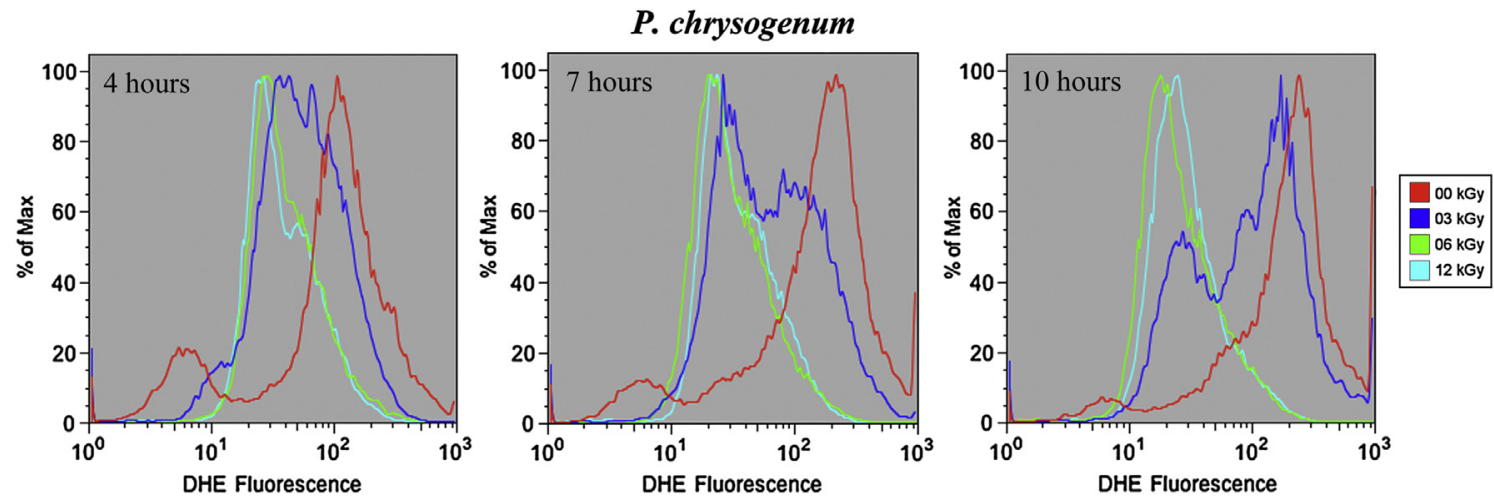

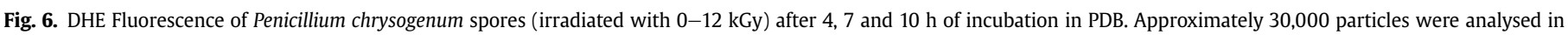
each run. 


\subsection{Effects of gamma irradiation on metabolic activity}

As previously described, gamma radiation promotes the formation of ROS within the cell (McNamara et al., 2003). For that reason, even at $0 \mathrm{~h}$, all irradiated samples presented higher DHE fluorescence than the control, with exception of $A$. nidulans (with $6 \mathrm{kGy}$ and higher doses; Table 3 ). It is worth mentioning that in this species, exposure to $6 \mathrm{kGy}$ and higher doses decreased the initial spore size (Table 1 ).

Some spores did survive lower radiation doses and were able to grow, with the ROS fluorescence increasing more intensely afterwards. As an example, the initial DHE fluorescence in P. chrysogenum after irradiation with $3 \mathrm{kGy}$ was about 6.8 times more intense than in the control (Table 3 ), however, the robust spores actually started to grow between 4 and $10 \mathrm{~h}$, and in the end, their DHE fluorescence was nearly 10 -fold higher than that of dead, unviable or otherwise stagnant spores (Fig. 6). Various environmental factors are responsible for the generation of ROS, ionizing radiation $(\alpha, \beta, \gamma$, and X-rays) and UV radiation are two examples. Recent works show that ROS also have a role in the regulation of proliferation, differentiation, extracellular signal transduction, ion transfer, and immune response (Dröge, 2002).

For $6 \mathrm{kGy}$, the DHE fluorescence of $P$. chrysogenum and A. nidulans, is initially high (caused by ROS production during irradiation) but it decreases with time, meaning that there is almost no metabolic activity (Table 3 ), which is confirmed by its reduced growth (Table 1). These results indicate that spores that were viable after irradiation with $6 \mathrm{kGy}$, were able to start growing, but stopped growing after $7 \mathrm{~h}$ of incubation. In A. nidulans, since an increase in fluorescence at $0 \mathrm{~h}$ was not observed, fluorescence was always low for $6 \mathrm{kGy}$ and higher doses.

Finally, with $12 \mathrm{kGy}$, the initial DHE fluorescence of $P$. chrysogenum and $A$. niger was considerably more intense than with lower doses, probably a consequence of the higher concentration of ROS formed by the ionizing radiation. Since very little viability levels or growth were detected in spores at that doses, the trend in DHE fluorescence decreased with time, as there was no biological activity to maintain ROS production (Table 3 ).

\section{Conclusions}

It is common to use the number of colony forming units as a way to assess the bioburden level, and therefore the contamination potential of one room or one document. After a decontamination treatment is applied, some resistant viable spores can nonetheless be severely affected by the treatment they underwent (i.e., genetically, chemically, or other), occasionally to the point that they might not be able to develop normally after germination.

By combining the analysis of FSC, SSC and fluorescence, we verified that, despite some of the spores were viable after irradiation they were incapable of growth after a few hours, meaning that they would be unlikely to damage a document either. This work suggests that lower radiation doses could possibly be applied effectively in the treatment of ancient objects, since effects of doses as low as $6 \mathrm{kGy}$ can prevent continued fungal growth of species we examined, even after they had started developing in liquid culture medium.

Overall, we were able to analyse the viability, growth and metabolic activity of irradiated spores using flow cytometry during the early stages of fungal spore growth. Results were consistent between radiation doses on all tested species: irradiated spores generally grew less, later, and were less metabolically active. Furthermore, FSC and SSC results were concordant with the DHE metabolic activity results: the DHE fluorescence intensity was higher in growing spores, but presented little variation in dead cells, sometimes even decreasing over time. The fluorescence intensity of PI in unviable cells was 5-7× higher than in viable cells, allowing the assessment of the effects of a sterilization treatment without the need to re-culture the cells.

It is worth emphasizing that these analyses can be performed immediately after a given treatment, without the need to reinoculate, incubate and perform colony counts. This method provides a rapid insight into the condition/resistance of different organisms. Furthermore, unculturable, yet viable spores can also be screened. This study with fungal cells treated with gamma irradiation, opens new doors to similar studies using other bioinactivation procedures.

\section{References}

Adamo, A.M., Giovannotti, M., Magaudda, G., Zappala, M.P., Rocchetti, F., Rossi, G. 1998. Effect of gamma rays on pure cellulose paper as a model for the study of a treatment of "biological recovery" of biodeteriorated books. Restaurator 19, 41-59.

Adamo, M., Brizzi, M., Magaudda, G., Martinelli, G., Plossi-Zappalà, M., Rocchetti, F. Savagnone, F., 2001. Gamma radiation treatment of paper in different environmental conditions: chemical, physical and microbiological analysis. Restaurator 22, 107-131.

Bennett, J.W., Kilch, M., 2003. Mycotoxins. Clinical Microbiology Reviews 16, 497-516.

Blank, G., Corrigan, D., 1995. Comparison of resistance of fungal spores to gamma and electron beam radiation. International Journal of Food Microbiology 26, 269-277.

Bradner, J.R., Nevalainen, K.M.H., 2003. Metabolic activity in filamentous fungi can be analysed by flow cytometry. Journal of Microbiological Methods 54, 193-201.

Breeuwer, P., Abee, T., 2000. Assessment of viability of microorganisms employing fluorescence techniques. International Journal of Food Microbiology 55, 193-200.

Brul, S., Nussbaum, S.K., Dielbandhoesing, S.K., 1997. Fluorescent probes for wall porosity and membrane integrity in filamentous fungi. Journal of Microbiological Methods 28, 169-178.

Da Silva, M., Moraes, A.M.L., Nishikawa, M.M., Gatti, M.J.A., Vallim de Alencar, M.A., Brandão, L.E., Nóbrega, A., 2006. Inactivation of fungi from deteriorated paper materials by radiation. International Biodeterioration \& Biodegradation 57, 163-167.

Dadachova, E., Casadevall, A., 2008. Ionizing radiation: how fungi cope, adapt, and exploit with the help of melanin. Current Opinion in Microbiology 11, $525-531$.

Davey, H., Kell, D., 1996. Flow cytometry and cell sorting of heterogeneous microbial populations: the importance of single-cell analyses. Microbiological Reviews 60, 641-696.

Davey, H.M., 2002. Flow cytometric techniques for the detection of microorganisms. Methods in Cell Science 24, 91-97.

Dröge, W., 2002. Free radicals in the physiological control of cell function. Physiological Reviews 82, 47-95.

Gessler, N.N., Aver'yanov, A.A., Belozerskaya, T.A., 2007. Reactive oxygen species in regulation of fungal development. Biochemistry 72, 1342-1364.

Green, L., Petersen, B., Steimel, L., Haeber, P., Current, W., 1994. Rapid determination of antifungal activity by flow cytometry. Journal of Clinical Microbiology 32 , 1088-1091.

Hanus, J., 1985. Gamma radiation for use in archives and libraries. Abbey Newsletter 9, 34-36.

McNamara, N.P., Black, H.I.J., Beresford, N.A., Parekh, N.R., 2003. Effects of acute gamma irradiation on chemical, physical and biological properties of soils. Applied Soil Ecology 24, 117-132.

Mesquita, N., Portugal, A., Videira, S., Rodríguez-Echeverría, S., Bandeira, A.M.L., Santos, M.J.A., Freitas, H., 2009. Fungal diversity in ancient documents. A case study on the Archive of the University of Coimbra. International Biodeterioration and Biodegradation 63, 626-629.

Osiewacz, H.D., 2002. Genes, mitochondria and aging in filamentous fungi. Ageing Research Reviews 1, 425-442.

Pointing, S.B., Jones, E.B.G., Jones, A.M., 1998. Decay prevention in water logged archaeological wood using gamma irradiation. International Biodeterioration \& Biodegradation 42, 17-24.

Prigione, V., Lingua, G., Marchisio, V.P., 2004. Development and use of flow cytometry for detection of airborne fungi. Applied and Environmental Microbiology 70, 1360-1365.

Saleh, Y.G., Mayo, M.S., Ahearn, D.G., 1988. Resistance of some common fungi to gamma irradiation. Applied and Environmental Microbiology 54, 2134-2135.

Samson, R.A., Houbraken, J., Thrane, U., Frisvad, J.C., Andersen, B., 2010. Food and Indoor Fungi. CBS-KNAW-Fungal Biodiversity Centre, Utrecht, the Netherlands, pp. $1-398$.

Scharbereiter-Gurtner, C., Piñar, G., Lubitz, W., Rölleke, S., 2001. Analysis of fungal communities on historical church window glass by denaturing gradient gel 
electrophoresis and phylogenetic 18S rDNA sequence analysis. Journal of Microbiological Methods 47, 345-354.

Shapiro, H., 2003. Practical Flow Cytometry. Wiley-Liss, New York.

Steinkamp, J.A., Lehnert, B.E., Lehnert, N.M., 1999. Discrimination of damage or dead cells by propidium iodide uptake in immunofluorescently labeled populations analyzed by phase-sensitive flow cytometry. Journal of Immunological Methods 226, 59-70.

Sterflinger, K., 2010. Fungi: their role in deterioration of cultural heritage. Fungal Biology Reviews 24, 47-55.

Sterflinger, K., Pinzari, F., 2011. The Revenge of Time: Fungal Deterioration of Cultural Heritage with Particular Reference to Books, Paper and Parchment. Environmental Microbiology. online at: http://onlinelibrary.wiley.com/doi/10. 1111/j.1462-2920.2011.02584.x/pdf.
Veal, D.A., Deere, D., Ferrari, B., Piper, J., Attfield, P.V., 2000. Fluorescence staining and flow citometry for monitoring microbial cells. Journal of Immunological Methods 243, 191-210.

Williams, S.C., Hong, Y., Danavall, D.C.A., Howard-Jones, M.H., Gibson, D., Frischer, M.E., Verity, P.G., 1998. Distinguishing between living and nonliving bacteria: evaluation of the vital stain propidium iodide and its combined use with molecular probes in aquatic samples. Journal of Microbiological Methods 32, 225-236.

Xiao, X., Zhi-ying, H., Ying-xu, C., Xin-qiang, L., Hua, L., Yi-chao, Qian, 2010. Optimization of FDA-PI method using flow cytometry to measure metabolic activity of the cyanobacteria, Microcystis aeruginosa. Physics and Chemistry of the Earth 36, 424-429.

Zyska, B., 1997. Fungi isolated from library materials: a review of the literature. International Biodeterioration \& Biodegradation 40, 43-51. 